\title{
The Relative Importance of the Interplanetary Electric Field and Magnetospheric Substorms on Partial Ring Current Development
}

\author{
C. Robert Clauer' and Robert L. McPherron
} Department of Earth and Space Science and Institute of Geophysics and Planetary Physics, University of California
Los Angeles, Calfformia 90024

\begin{abstract}
During periods of substorm activity, midlatitude geomagnetic data often reveal a depression in the northward component of the magnetic field in a limited region near the dusk meridian. This magnetic signature has usually been attributed to a partial ring current which forms as a result of the substorm activity. It is intriguing, however, that not all substorms are associated with the presence of a partial ring current. Results of a study which examines the relationship between substorm activity and the formation of the partial ring current will be presented. Using midlatitude magnetic data, the partial ring current may be parameterized by the maximum strength of the field depression which develops near the dusk meridian. This parameter has been related to time integral of the $A E, A U$ and $A L$ indices as well as to the dawn-to-dusk component of the interplanetary electric field. The results show little relation of the partial ring current parameter to the measures of substorm activity but a high correlation with the interplanetary electric field. An investigation of timing relationships is also reported. A comparison of the onset times of auroral zone activity and partial ring current growth shows that the partial ring current is as likely to begin to develop before the onset of auroral zone activity as after. A southward turning of the interplanetary magnetic field however, consistently precedes the establishment of a partial ring current. These results are interpreted to indicate that enhancement of the fractional solar wind emf applied across the magnetosphere plays a direct causative role in the development of the partial ring current.
\end{abstract}

\section{INTRODUCTION}

The existence of longitudinal asymmetry in the geomagnetic disturbance field at low and midlatitudes during magnetic storms has been well established [Sugiura and Chapman, 1960; Akasofu and Chapman, 1964]. The asymmetric disturbance is superposed upon a symmetric field depression attributed to the existence of a symmetric ring current. Magnetic measurements on board spacecraft and on the ground indicate that an asymmetric development of the ring current occurs during the main phase of a geomagnetic storm with the greatest magnetic perturbation occurring in the dusk and evening region [Langel and Cain, 1968; Cahill, 1966, 1970, 1973; Coleman and Cummings, 1968; Cummings et al., 1968; Fukushima, 1972]. During the recovery of the storm, the asymmetric portion of the disturbance decays rapidly and a symmetric magnetic depression remains which decays on the time scale of several days. A longitudinally limited partial ring current with feld aligned closure through the auroral ionosphere has been suggested to explain the asymmetric portion of the disturbance [Cummings, 1966; Kawasaki and Akasofu, 1971; Kamide and Fukushima, 1972; Fukushima, 1972; Fukushima and Kamide, 1973, and references therein].

The ring current is generally thought to be produced by the charge dependent drift of trapped energetic plasma in the inner magnetosphere. The first direct observation of the low energy proton distribution thought to be primarily responsible for the ring current was reported by Frank [1967]. Direct observations of asymmetric enhancements of the proton energy density near dusk during storm development have been reported by Frank [1970] and by Smith and Hoffman [1973].

In this report, we examine the development of the partial ring current and its relationship to various magnetospheric

\footnotetext{
' Now at Institute for Plasma Research, Stanford University, Stanford, California 94305.

Copyright (c) 1980 by the American Geophysical Union.
}

processes. A major problem exists in establishing the relative importance of an enhanced electrostatic convection field and the substorm associated induction electric fields on the development of the partial ring current since substorms typically occur during periods of enhanced electrostatic field.

Davis and Parthasarathy [1967] suggested that ring current development was a direct result of substorm expansions. This speculation was based on an analysis of hourly average values of $A E$ and $D s t$ which indicated that ring current enhancements were burst-like and followed substorms by an hour or more. This conclusion was criticized by Rostoker [1972]. Akasofu and Meng [1968] considered 20 substorms which produced negative bays at auroral latitudes and positive bays at midlatitudes. Each negative bay in the auroral zone was associated with a field decrease at midlatitudes near dusk and was interpreted as a ring current enhancement produced by the substorm.

DeForest and McIlwain [1971] using equatorial observations of charged particles measured by the geostationary satellite ATS 5 reported intrusions of hot plasma which occurred with a one-to-one correspondence to magnetospheric substorms. They speculated that substorm processes inject a discrete 'plasma cloud' into the ring current region. The suggestion was made by Bogott and Mozer [1973] that substorm associated proton bursts are injected into the night side magnetosphere and form the partial ring current.

On the other hand, Burton et al. [1975] developed an empirical relationship between solar wind parameters and ring current development without regard for substorm activity. Measurements of the solar wind dynamic pressure and interplanetary electric field (IEF) were used to predict Dst very accurately for several storm time periods. Kamide [1974] showed that growth of the DR or ring current field on the earth's surface is more closely related to time variations of the north-south component of the interplanetary magnetic field (IMF) than to the $A L$ index.

That presubstorm convection enhances the ring current was 
TABLE 1. Geographic and Geomagnetic Coordinates of Low, Middle, and High Latitude Observatories

\begin{tabular}{|c|c|c|c|c|c|}
\hline \multirow{2}{*}{$\begin{array}{c}\text { Station } \\
\text { Code }\end{array}$} & \multirow[b]{2}{*}{ Station } & \multicolumn{2}{|c|}{ Geographic } & \multicolumn{2}{|c|}{ Geomagnetic } \\
\hline & & W. Longitude & Latitude & E. Longitude & Latitude \\
\hline \multicolumn{6}{|c|}{ Low and Mid-Latitude Observatories } \\
\hline MB & M'Bour & $16^{\circ} 58^{\prime}$ & $14^{\circ} 24 \mathrm{~N}$ & $55.0^{\circ}$ & $21.3^{\circ}$ \\
\hline TW & Trewlew & $65^{\circ} 19^{\prime}$ & $43^{\circ} 15^{\prime} \mathrm{S}$ & $3.2^{\circ}$ & $-31.8^{\circ}$ \\
\hline SJ & San Juan & $66^{\circ} 09^{\prime}$ & $18^{\circ} 07^{\prime} \mathrm{N}$ & $3.1^{\circ}$ & $29.6^{\circ}$ \\
\hline CE & Cuba & $82^{\circ} 08^{\prime}$ & $22^{\circ} 68^{\prime} \mathrm{N}$ & $345.4^{\circ}$ & $34.1^{\circ}$ \\
\hline DS & Dallas & $96^{\circ} 45^{\prime}$ & $32^{\circ} 59 / \mathrm{N}$ & $327.7^{\circ}$ & $43.0^{\circ}$ \\
\hline BD & Boulder & $105^{\circ} 14^{\prime}$ & $40^{\circ} 08^{\prime} \mathrm{N}$ & $316.5^{\circ}$ & $49.0^{\circ}$ \\
\hline TU & Tucson & $110^{\circ} 50^{\prime}$ & $32^{\circ} 15^{\prime} \mathrm{N}$ & $312.2^{\circ}$ & $\mathbf{4 0 . 4 ^ { \circ }}$ \\
\hline TA & Tahiti & $149^{\circ} 37^{\prime}$ & $17^{\circ} 33^{\prime} \mathrm{S}$ & $282.7^{\circ}$ & $-15.3^{\circ}$ \\
\hline HO & Honolulu & $158^{\circ} 00^{\prime}$ & $21^{\circ} 19 \mathrm{~N}$ & $266.5^{\circ}$ & $21.1^{\circ}$ \\
\hline PM & Port Moresby & $212^{\circ} 51^{\prime}$ & $9^{\circ} 24^{\prime} \mathrm{S}$ & $217.9^{\circ}$ & $-18.6^{\circ}$ \\
\hline TO & Toolangi & $214^{\circ} 32^{\prime}$ & $37^{\circ} 32^{\prime} \mathrm{S}$ & $220.8^{\circ}$ & $-46.7^{\circ}$ \\
\hline $\mathbf{K A}$ & Kakioka & $219^{\circ} 49^{\prime}$ & $36^{\circ} 14 \mathrm{~N}$ & $206.0^{\circ}$ & $26.0^{\circ}$ \\
\hline GN & Gnangara & $244^{\circ} 03^{\prime}$ & $31^{\circ} 47^{\prime} \mathrm{S}$ & $185.8^{\circ}$ & $-43.2^{\circ}$ \\
\hline PY & Patrony (Irkutsk) & $255^{\circ} 33^{\prime}$ & $52^{\circ} 10 \mathrm{~N}$ & $174.7^{\circ}$ & $40.7^{\circ}$ \\
\hline HY & Hyderabad & $281^{\circ} 27^{\prime}$ & $17^{\circ} 25 \mathrm{~N}$ & $148.9^{\circ}$ & $7.6^{\circ}$ \\
\hline YB & Yangi-Bazar (Tashkent) & $290^{\circ} 22^{\prime}$ & $41^{\circ} 18^{\prime} \mathrm{N}$ & $144.0^{\circ}$ & $32.3^{\circ}$ \\
\hline DT & Dusbeti (Tibilisi) & $315^{\circ} 17^{\prime}$ & $42^{\circ} 04^{\prime} \mathrm{N}$ & $122.0^{\circ}$ & $36.6^{\circ}$ \\
\hline ST & Stepanovka (Odessa) & $329^{\circ} 07^{\prime}$ & $46^{\circ} 46^{\prime} \mathrm{N}$ & $111.1^{\circ}$ & $43.6^{\circ}$ \\
\hline HR & Hermanus & $340^{\circ} 46^{\prime}$ & $34^{\circ} 25^{\prime} \mathrm{S}$ & $80.5^{\circ}$ & $-33.3^{\circ}$ \\
\hline \multicolumn{6}{|c|}{ High Latitude Observatories } \\
\hline LR & Leirvogur & $21^{\circ} 42^{\prime}$ & $64^{\circ} 11^{\prime} \mathrm{N}$ & $71.0^{\circ}$ & $70.2^{\circ}$ \\
\hline NAS & Narssarssuaq & $45^{\circ} 12^{\prime}$ & $61^{\circ} 06^{\prime} \mathrm{N}$ & $37.0^{\circ}$ & $71.0^{\circ}$ \\
\hline TH & Thule & $69^{\circ} 10^{\prime}$ & $77^{\circ} 29^{\prime} \mathrm{N}$ & $263.4^{\circ}$ & $88.9^{\circ}$ \\
\hline GWR & Great Whale River & $77^{\circ} 47^{\prime}$ & $55^{\circ} 16^{\prime} \mathrm{N}$ & $347.4^{\circ}$ & $66.6^{\circ}$ \\
\hline FC & Fort Churchill & $94^{\circ} 06^{\prime}$ & $58^{\circ} 48^{\prime} \mathrm{N}$ & $322.8^{\circ}$ & $68.7^{\circ}$ \\
\hline BL & Baker Lake & $96^{\circ} 02^{\prime}$ & $64^{\circ} 20 \mathrm{~N}$ & $315.2^{\circ}$ & $73.8^{\circ}$ \\
\hline ME & Meanook & $113^{\circ} 20^{\prime}$ & $54^{\circ} 37 \prime \mathrm{N}$ & $301.0^{\circ}$ & $61.8^{\circ}$ \\
\hline SI & Sitka & $135^{\circ} 20^{\prime}$ & $57^{\circ} 04^{\prime} \mathrm{N}$ & $275.3^{\circ}$ & $60.0^{\circ}$ \\
\hline $\mathrm{CO}$ & College & $147^{\circ} 50^{\prime}$ & $64^{\circ} 52^{\prime} \mathrm{N}$ & $256.5^{\circ}$ & $64.6^{\circ}$ \\
\hline BW & Barrow & $156^{\circ} 45^{\prime}$ & $71^{\circ} 18 \mathrm{~N}$ & $241.1^{\circ}$ & $68.5^{\circ}$ \\
\hline UE & Cape Wellen & $169^{\circ} 50^{\prime}$ & $66^{\circ} 10 \mathrm{~N}$ & $237.1^{\circ}$ & $61.8^{\circ}$ \\
\hline TI & Tixie Bay & $231^{\circ} 00^{\prime}$ & $71^{\circ} 35 \mathrm{~N}$ & $191.4^{\circ}$ & $60.4^{\circ}$ \\
\hline $\mathrm{CC}$ & Cape Chelyuskin & $255^{\circ} 43^{\prime}$ & $77^{\circ} 43^{\prime} \mathrm{N}$ & $176.5^{\circ}$ & $66.3^{\circ}$ \\
\hline DI & Dixon Island & $286^{\circ} 27^{\prime}$ & $73^{\circ} 33^{\prime} \mathrm{N}$ & $161.6^{\circ}$ & $63.0^{\circ}$ \\
\hline so & Sodankyla & $333^{\circ} 22^{\prime}$ & $67^{\circ} 22^{\prime} \mathrm{N}$ & $120.0^{\circ}$ & $63.8^{\circ}$ \\
\hline NU & Nurmijarvi & $335^{\circ} 21^{\prime}$ & $60^{\circ} 31 \mathrm{~N}$ & $112.6^{\circ}$ & $57.9^{\circ}$ \\
\hline
\end{tabular}

suggested by Huage and Soraas [1975] based on observations of a substorm on January 24, 1969. The IMF turned southward at $1100 \mathrm{UT}$. This was followed by a decrease in the magnetic field measured at Guam and Honolulu which was interpreted as energy being put into the ring current. A substorm onset occurred at 1310 UT. Precipitation of $>115 \mathrm{keV}$ protons recorded by the polar orbiting satellite ESROLA in the early evening sector increased by 3 orders of magnitude over presubstorm levels measured on a pass $15 \mathrm{~min}$ into the substorm expansion. The authors suggest that precipitation as a loss mechanism for the ring current is greatly enhanced during the substorm expansion while injection into the ring current began prior to the substorm onset.

Recently much theoretical effort has been directed toward understanding the effects of the potential drop imposed across the magnetospheric cavity as a result of the magnetosphere's interaction with the solar wind. Theories describing magnetospheric plasma convection under the influence of a suddenly enhanced uniform or nearly uniform cross magnetospheric electric field and radial corotational electric field have been developed by Chen [1970, 1974], Kivelson and Southwood [1975a, b], Walker and Kivelson [1975], Cowley and AshourAbdalla [1976a, b], Ejiri [1978], and Ejbi et al. [1978]. Selfconsistent calculations using modeled ionospheric con- ductivities and hot magnetospheric plasma have been reported by Wolf [1970] and Jaggi and Wolf [1973]. The trajectories of the convecting particles in the inner magnetosphere where gradient and curvature drifts become important are very complex. Models of this complex energy-dependent plasma convection based on simple field geometries have been very successful in explaining much of the plasma data obtained by spacecraft in the inner magnetosphere.

It is not clear whether the development of the ring current results directly from substorm expansions, or whether both substorms and the ring current are responding individually to a third factor. In this report we present results of a quantitative investigation of the relationship of ring current enhancement to individual, isolated substorms and to interplanetary plasma conditions.

Rostoker [1972] notes that the asymmetric development of the ring current is at the noise level of the Dst index and that care must be taken in using $D s t$ to measure small enhancements of the ring current during substorms. We note that the asymmetric field depression near dusk attributed to the partial ring current provides the initial indication of ring current enhancement. Thus, an index of the partial ring current is potentially a more sensitive measure of ring current enhancement than is the Dst index. To better establish the relationship of 


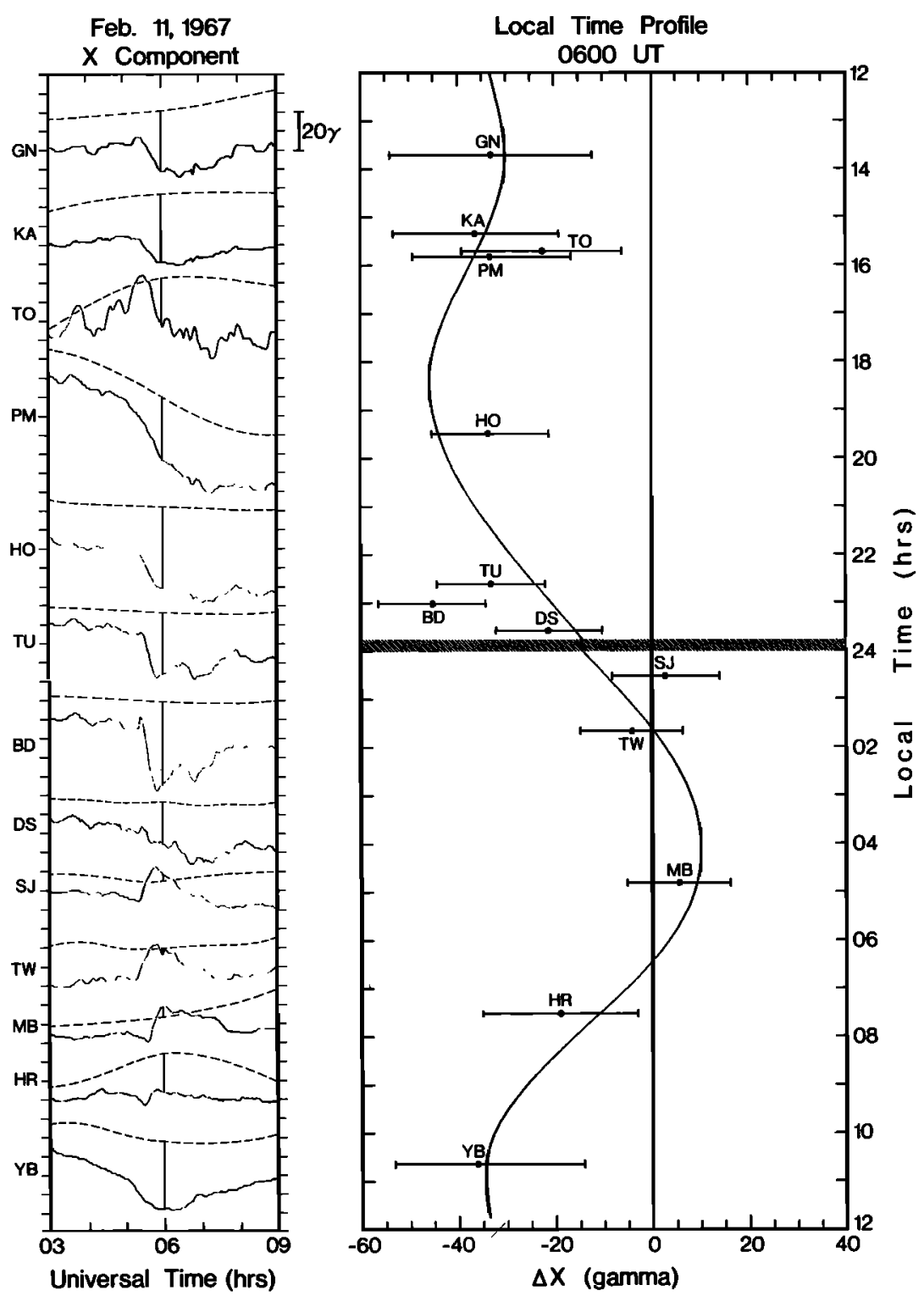

Fig. 1. (Left) Midlatitude observations of the north-south component (solid line) and model quiet magnetic field (dashed line) on February 11, 1967. Vertical lines at $0600 \mathrm{UT}$, indicate the difference between observation and quiet field at each observatory. (Right) Local time profile of the $\Delta X$ component at $0600 \mathrm{UT}$, the peak of a substorm expansion. Dots correspond to the deviation from the quiet field at each station plotted as a function of the local time position of the station. Error bars indicate the uncertainty of the quiet field at each local time. The smooth curve is a least squares fit to the data points using a series of cubic splines. Discontinuity in the curve at $2400 \mathrm{LT}$ is caused by the day boundary.

ring current enhancement to substorm activity and to the interplanetary electric field, we have examined isolated substorms using high time resolution (2.5 min) data from ground magnetic observatories and we have used parameters which are sensitive to enhancements of the partial ring current. In the following sections we will discuss the analysis techniques and some examples which illustrate the techniques. This will be followed by the results of a statistical investigation.

\section{EXPERIMENTAl Procedure}

\section{Description}

The magnetic signatures of the symmetric and partial ring currents are best observed by using a chain of midlatitude ground magnetic observatories. Data from such a world-wide chain of observatories can be used to display the spatial and temporal development of these large scale current systems
[Troshichev and Feldstein, 1972; Clauer and McPherron, 1978]. The data processing and display techniques used in this paper are similar to those discussed by Clauer and McPherron [1974]. Several improvements to the analysis techniques and a thorough error analysis are discussed by Claver et al. [1980].

In the first step of the analysis, the average quiet magnetic field which includes the diurnal, seasonal and secular variations is subtracted from the measurements at each observatory in our longitudinal chain shown in Table 1 . The data are then normalized to a fixed latitude of $30^{\circ}$ [Clauer et al., 1973]. The disturbance values which remain are fitted by a smooth local time profile using a least square technique and cubic spline functions.

This procedure is illustrated in Figure 1. Along the left side of the figure are plotted measurements of the geomagnetic $X$ (north-south) component (solid line) along with the model 


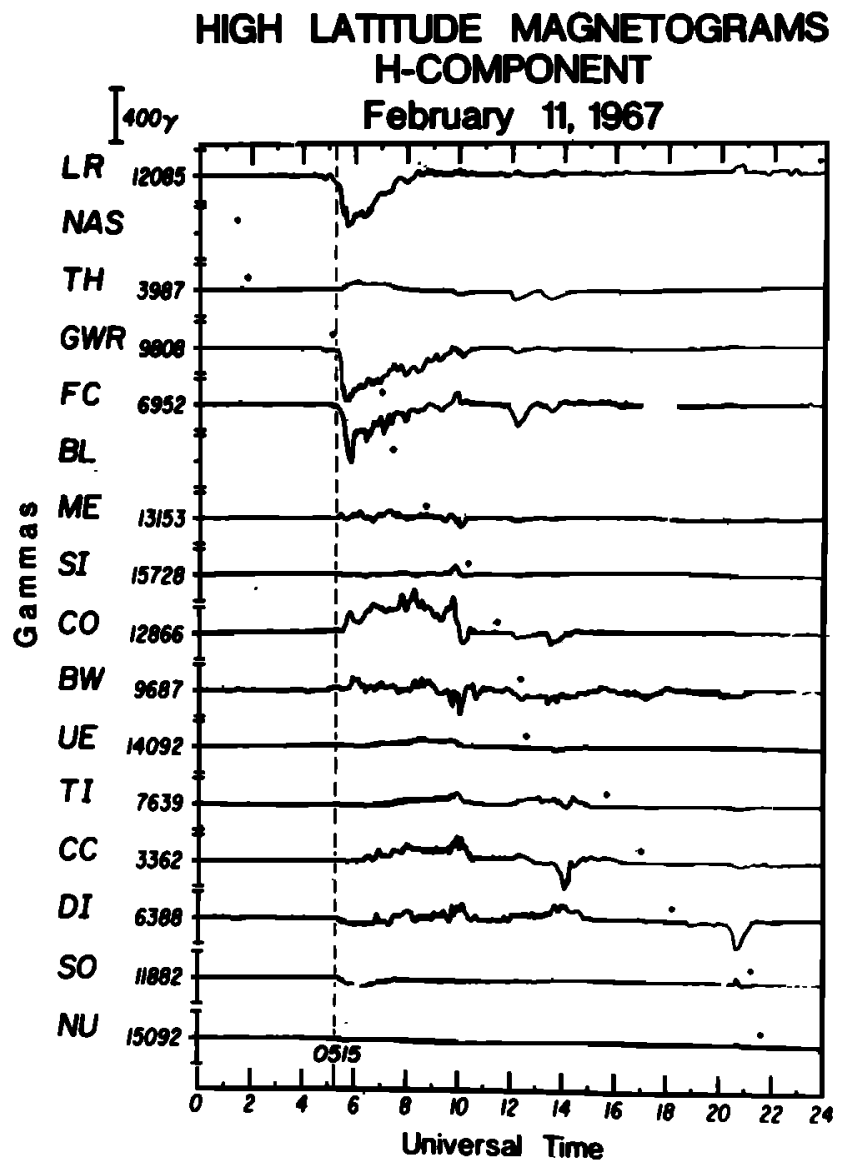

Fig. 2. The $H$ component magnetograms from high latitude observatories on February 11, 1967. Vertical line at 0515 UT marks a substorm onset. The crosses above each trace indicate local geomagnetic midnight at the respective observatory.

quiet field (dashed line) predicted for each station in a chain of midlatitude observatories.

A substorm onset at 0515 UT is indicated by the positive bays at SJ, TW and MB. Associated with this substorm is a large decrease in the horizontal field observed at many other stations. The largest decrease is observed at BD and TU suggesting a large enhancement of the partial ring current. The data values plotted vertically at the right were obtained by subtracting the model quiet field from the measured magnetic field at 0600 UT, the peak of the substorm expansion seen at MB. The data values are plotted as a function of the local time position of each station. The error bars on the data points represent the uncertainty of the model quiet field and vary as a function of local time, being the greatest near local noon where the strength and variability of the Sq currents are the greatest. The smooth profile through the data points was computed by a least squares algorithm using cubic splines.

Using digital data, perturbation profiles can be computed at 2.5-min intervals in universal time. The results can be displayed in the form of a universal time-local time (UT-LT) map of the magnetic disturbance [Claver and McPherron, 1974]. By drawing contours of constant magnetic perturbation, both the spatial and temporal development of magnetic disturbances can be displayed. A substorm will appear as nested contours of enhanced field near local midnight while the partial ring current will appear as nested contours of depressed field near dusk. The error of each local time profile varies from about $\pm 24 \gamma$ near local noon to $\pm 9 \gamma$ near local midnight. This error is based upon \pm 2 standard deviations of the spread of data used to compute the quiet field model and is discussed in detail by Claver et al. [1980]. Since errors in the estimate of the quiet field are highly correlated for periods of 3 or 4 hours much of the error may be eliminated when considering events of this duration. This is done by subtracting the profile at the onset of the event from later profiles; the correlated errors in the quiet field are removed and the resulting profiles represent the effect of currents which develop during the interval of time between profiles. This procedure typically reduces the error to about $\pm 6 \gamma$.

The local time profiles of the midlatitude magnetic disturbance created in the above manner may be used to obtain parameters which characterize the disturbance [Clauer and McPherron, 1974; Clauer et al., 1980]. The substorm expansion current produces an enhancement in the northward field in the night region while the partial ring current produces a depression in the northward field centered near dusk. The $\Delta X$ profile can be used to compute parameters of both the partial ring current and the substorm expansion current at the peak of the disturbances. The magnitude of enhancement is characterized by the maximum or minimum of the profile; the extent is defined as the full width at half maximum (or minimum) of the perturbation; the size is taken to be the product of the magnitude and extent; and the central meridian is given by the local time of the maximum or minimum value.

In this report we will show the results obtained by applying these techniques to an investigation of the partial ring current. The investigation examines two mechanisms which have been suggested to account for plasma injection and the subsequent development of the partial ring current. In one mechanism, the large inductive electric fields produced during substorm expansions are responsible for the plasma injection. In the second mechanism, injection results from an enhancement of the cross tail emf produced by the magnetosphere's interaction with the solar wind. Ground magnetic data are used to measure partial ring current development and substorm activity. The duskward component of the solar wind electric field computed from the solar wind velocity and the northward component of the IMF is used to infer periods of enhanced solar wind emf applied to the magnetosphere. The following individual events exemplify the analysis and illustrate the results which have been obtained.

\section{Examples}

The onset of an isolated substorm expansion occurred at 0515 UT on February 11, 1967. High latitude magnetograms for this day are shown in Figure 2. The station names and locations are listed in Table 1. Figure 3 displays the dawn-dusk $\left(E_{y}\right)$ component of the interplanetary electric field (IEF) along with the auroral zone indices $A U$ and $A L$ and a UT-LT map of the midlatitude ground magnetic disturbance. The $E_{y}$ component is derived from measurements of $B_{z}$ in the IMF and the solar wind velocity according to the equation $E_{y}=V B_{z}$. Negative values of $E_{y}$ indicate that the IEF is directed from dawn to dusk' and these periods have been shaded on the $E_{y}$ trace. Local time or position around the earth is plotted along the vertical axis of the UT-LT map with local noon at the top and bottom and local midnight in the center. Universal time is plotted along the horizontal axis. Contours of the magnetic disturbance are drawn at $5 \gamma$ intervals. The midlatitude field 


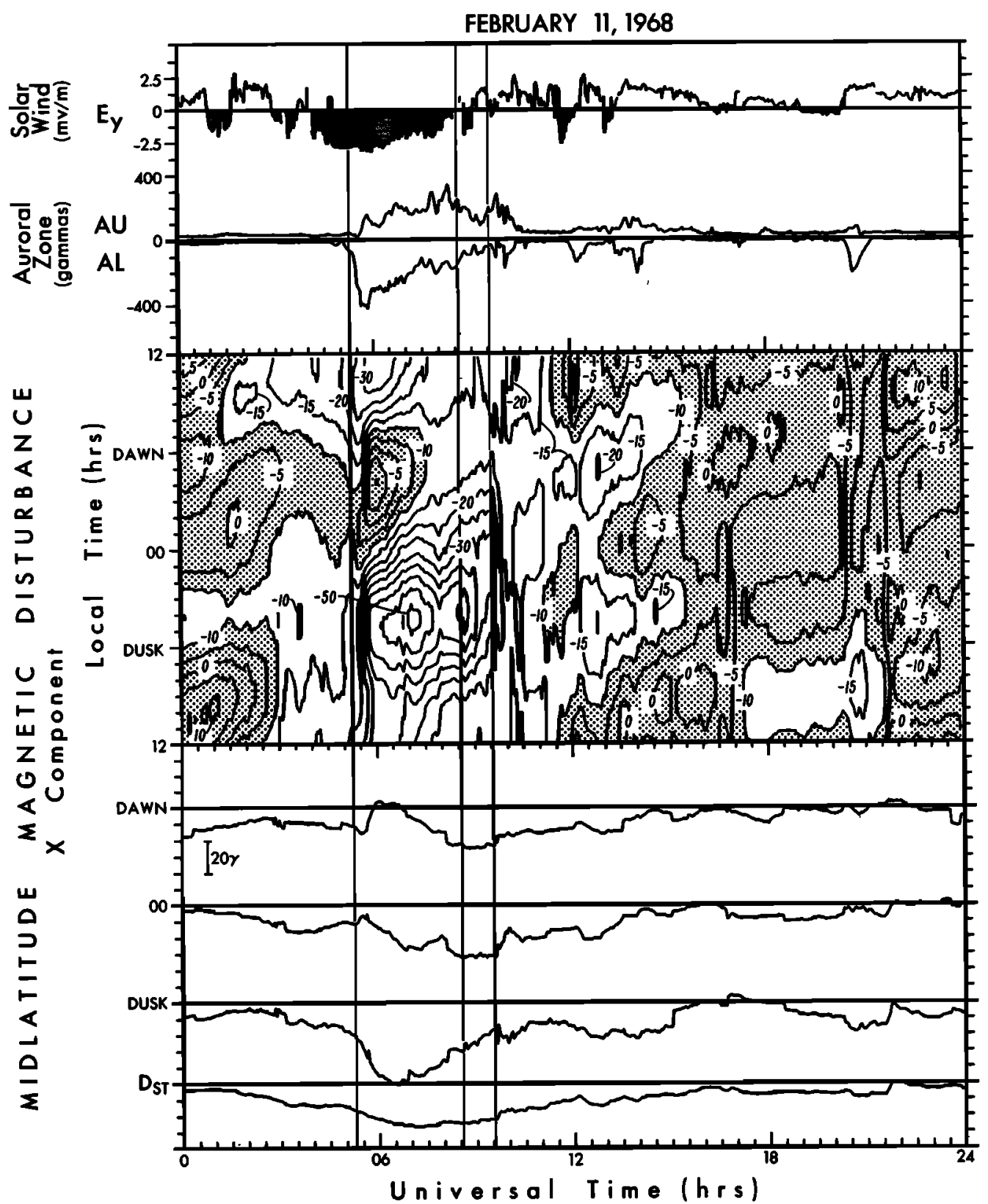

Fig. 3. (a) The dawn-dusk component of the interplanetary electric field. Negative $E_{j}$ indicates a duskward orientation. Periods of duskward oriented field have been shaded. (b) The $A U$ and $A L$ auroral indices. (c) The UT-LT map of the midlatitude magnetic disturbance. Contours are drawn at $5 \gamma$ intervals. (d) Traces of the midlatitude magnetic disturbance at fixed local times: dawn, midnight and dusk. (e) The Dst index.

prior to the substorm expansion was everywhere depressed and contour levels greater than $-10 \gamma$ have been shaded. The traces under the map show the midlatitude magnetic perturbations at fixed local times of dawn, midnight and dusk. The bottom trace is the average midlatitude field perturbation or Dst.

A vertical line at 0515 UT marks the substorm onset. The UT-LT map shows a region of enhanced field centered near $0400 \mathrm{LT}$ which is the signature of the substorm expansion. A very large field depression develops simultaneously near dusk. The depression continues to grow during the substorm recovery reaching a minimum value of about $-50 \gamma$. The location of the maximum depression is near 2000 LT. A vertical line at 0835 UT marks the time when the partial ring current begins a slow decay. A third vertical line at 0932 UT marks a more rapid decay of the partial ring current. Note that the development of the partial ring current occurs during a period of steady, enhanced, duskward IEF and decay begins as $E_{y}$ approaches zero and changes sign.

The example in Figure 3 will be compared with a series of substorms which occurred on January 23 and 24, 1968. Data for these days are shown in Figures 4 and 5 respectively using a format identical to Figure 3. Contours on the UT-LT map are drawn at $5 \gamma$ intervals and contour levels greater than zero are shaded. Vertical lines mark the onsets of high latitude negative bays and the associated midlatitude positive bays. The indicated substorm onsets are 1602 and 2000 UT on January 23 and 0855, 1140, 1435, and 1827 UT on January 24.

While several of the substorms produce very weak midlatitude positive bays, the expansions on 2000 UT on January 


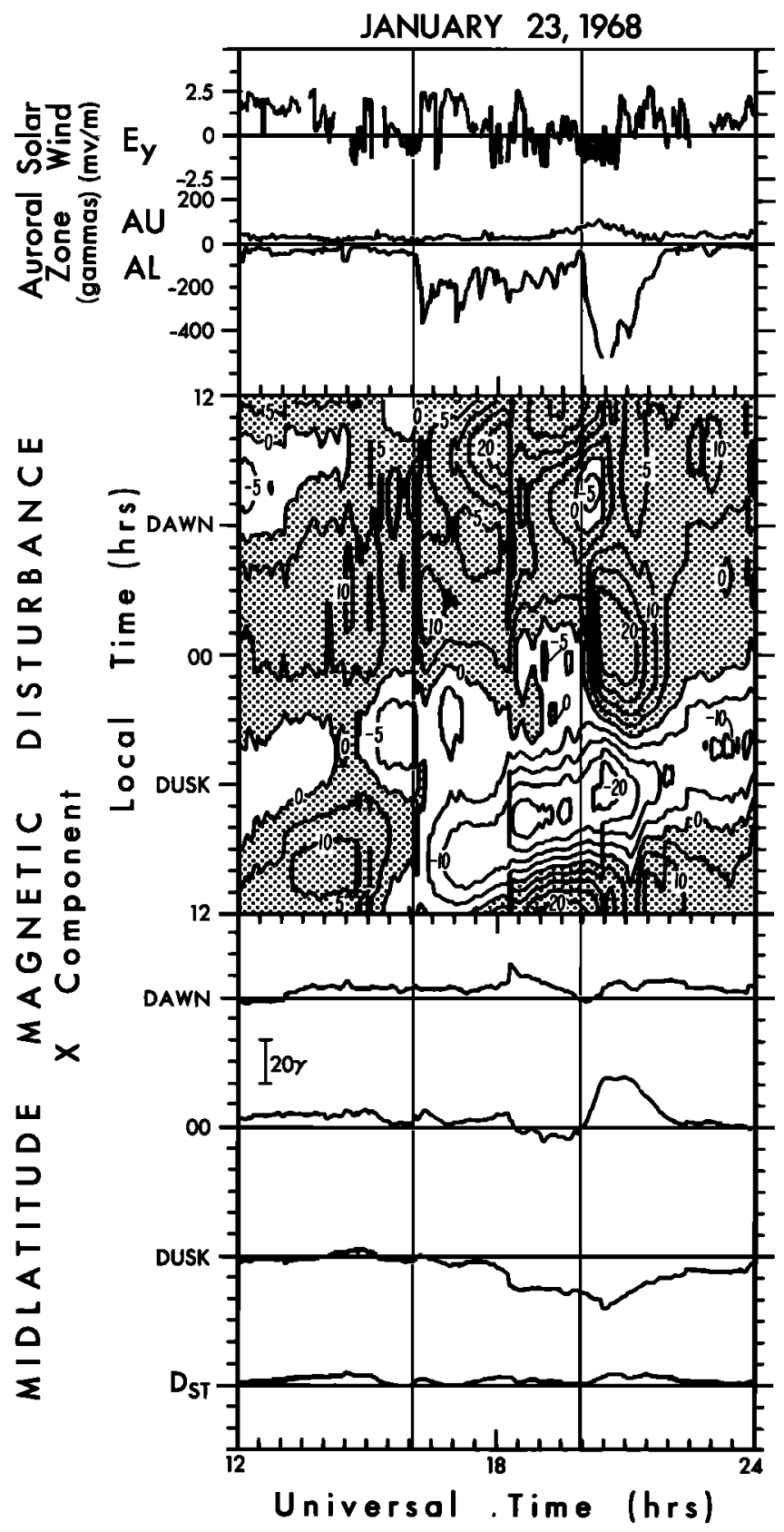

Fig. 4. Same format as Figure 3.

23 and 1827 UT on January 24 produce midlatitude disturbances that are larger than that produced by the sustorm expansion on February 11, 1967. In general, one would have to characterize the substorm activity on January 23 and 24, as greater than the activity on February 11 . In contrast to the sustained enhancement of the duskward IEF on February 11, $E_{y}$ can be described as having frequent short duration negative fluctuations during January 23 and 24.

The dusk trace of the midlatitude disturbance can be used to indicate enhancement of the partial ring current. On January 23, partial ring current enhancement begins at about 1800 UT. The magnetic depression grows to about $20 \gamma$ at 2030 UT. On January 24, the maximum partial ring current field depression is about $25 \gamma$ which is substantially smaller than the partial ring current depression which occurred on February 11.
These examples suggest that substorm expansions may play a role in the development of the partial ring current. For example, on January 24 , a $20 \gamma$ dusk depression in the midlatitude field is associated with the 1140 UT substorm expansion which occurred while $E_{y}$ was positive. However, the enhancement of the magnetosphere's electrostatic field which results from a sustained enhancement of the solar wind duskward emf applied across the magnetosphere also appears to produce a considerable effect. This is demonstrated by the partial ring current disturbance on February 11 during a period of sustained duskward $E_{y}$ as constrasted with the small partial ring current disturbances associated with the greater substorm activity on January 23 and 24.

A final example which suggests that development of the partial ring current can precede the onset of a major negative bay in the auroral zone or positive bay at mid-latitudes will be shown. Figure 6 displays the solar wind velocity and density, the north-south $\left(B_{z}\right)$ component of the IMF, along with midlatitude and auroral zone ground magnetic data for February 25,1967 . Two large substorms occurred on this day, both associated with large partial ring current depressions. Contours on the UT-LT map are drawn at $10 \gamma$ intervals and positive contours are shaded. A vertical line at 0430 UT marks the first onset of a large auroral zone negative bay. Prior to this onset, there was a large southward turning of the IMF associated with a sudden decrease of the solar wind dynamic pressure. The onset of a second large auroral zone negative bay occurred at 1655 UT and is also marked by a vertical dashed line. The solar wind velocity and density remain stable during this substorm. Both substorms occurred during periods of large sustained southward IMF. Since the solar wind dynamic pressure is constant during the second substorm, this event is more suitable for examination than the earlier substorm.

Vertical lines before each negative bay onset mark the onset time chosen for the magnetic field depression near dusk. The onset of the dusk depression is not clearly discernible from the UT-LT map in Figure 6 alone. In this work a careful examination of several data displays has been used to estimate the onset time of the partial ring current magnetic disturbance. For example, the development of the partial ring current disturbance associated with the 1655 UT substorm is shown more clearly in Figure 7. To create this map, the local time profile at 1500 UT was subtracted from all later profiles. Thus, we are able to display the magnetic effects of currents which develop after 1500 UT. The subtraction used in this technique further reduces the uncertainty in the UT-LT map over time periods of a few hours. The reduction in uncertainty results because errors in the quiet field model at any particular observatory used to generate the map are highly correlated over time periods of several hours [Clauer et al., 1980].

Negative perturbations in Figure 7 are shaded and a vertical line at 1655 UT marks the onset of the substorm expansion. The dusk depression clearly begins prior to the substorm expansion. The onset time is taken to be the point where the time rate of change of the field near dusk becomes $-0.2 \gamma / \mathrm{min}$ or less. To select this point we use the original dusk station magnetograms, the UT-LT maps and the computed value of the time rate of change of the dusk field. In cases where the onset remains ambiguous, we create several 'normalized' maps such as the one in Figure 7 using 'normalization' times in the vicinity of the onset. Estimates of the partial ring current onset time obtained from the different data displays generally agree within $30 \mathrm{~min}$. The onset time of the partial ring 


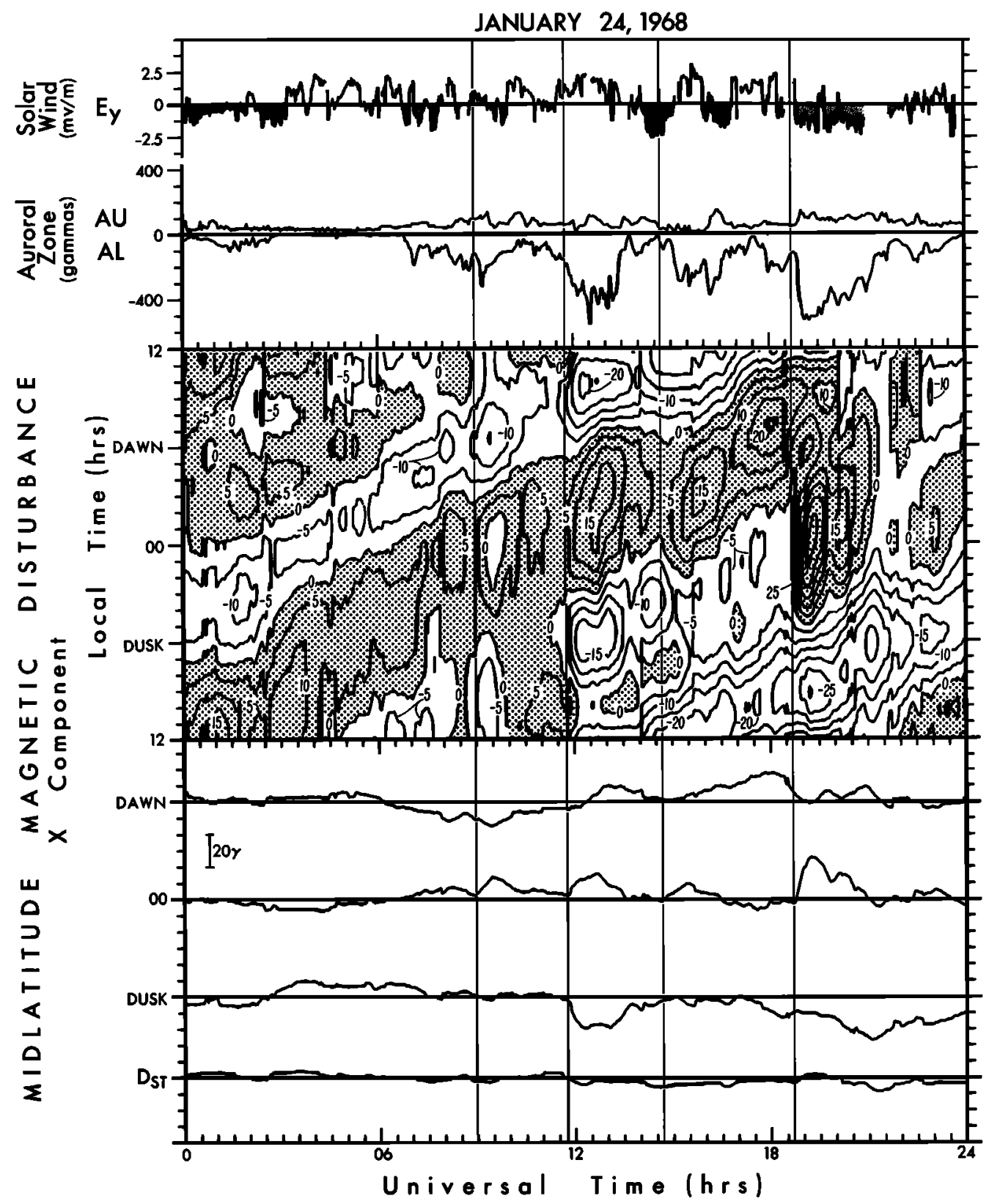

Fig. 5. Same format as Figure 3.

current for the event illustrated in Figure 7 was chosen to be $1600 \mathrm{UT}$.

There is an indication that the substorm expansion plays an additional role in the development of the partial ring current since the rate of field depression near dusk increases at the onset of the substorm.

Although the above examples indicate that substorm processes can affect the development of the partial ring current, they also suggest that an enhancement of the duskward IEF may have greater influence on partial ring current development. They suggest that a much stronger partial ring current will develop in the presence of a sustained enhancement of the duskward IEF than will develop in response to substorm activity associated with only brief enhancement of the duskward IEF. In addition, the partial ring current can begin growth in the absence of substorm activity but following an enhancement of the duskward IEF. In the following section we will present the results of a statistical investigation of these relationships.

\section{Statistical Results}

In the following, two types of relationships were investigated-magnitude relationships and temporal relationships. The method of selecting events for the analysis is shown in Figure 8. Substorms were required to be well defined and isolated; however, multiple onset events were included as single events. Using these criteria, events were selected to fill two classes defined by the magnitude of the partial ring current disturbance (PRC). The classes were defined by a PRC magnitude either less than $15 \gamma$ (weak) or greater than $15 \gamma$ (moderate to large). Events within each class were selected according to the magnitude of the substorm associated midlatitude positive bay. For the two classes the distributions of the magnitudes of the midlatitude positive bays were selected to be 


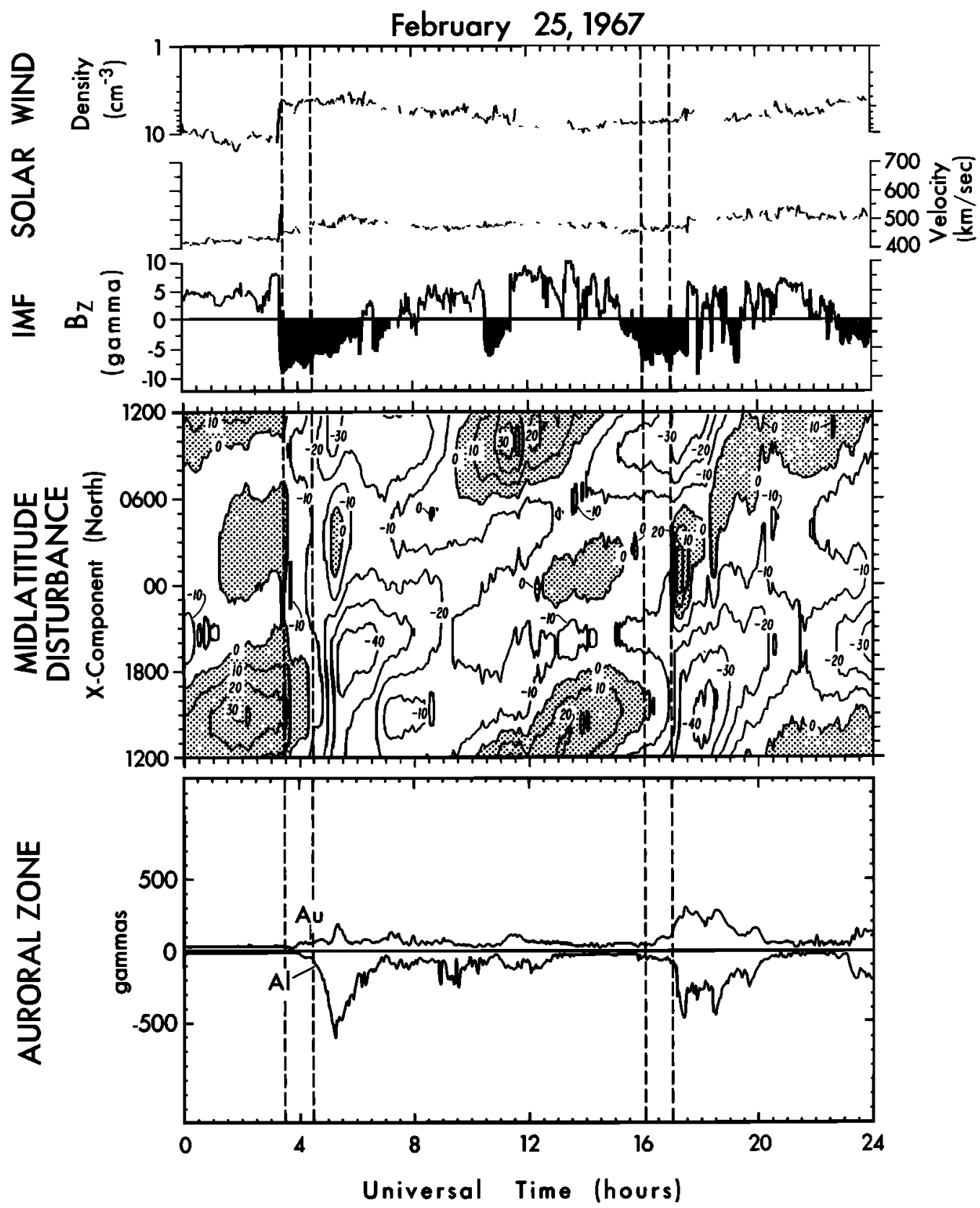

Fig. 6. (a) The solar wind number density. (b) The solar wind velocity. (c) The north-south component of the IMF in GSM coordinates. Periods of southward $B_{z}$ have been shaded. (d) The UT-LT map of the midlatitude magnetic disturbance. Contours are drawn at $10 \gamma$ intervals. (e) The $A U$ and $A L$ indices.

similar as shown in Figure 8. That this selection can be accomplished with relative ease is significant and important to the conclusions reached in this report.

First we will present the results obtained by investigating the relation between the magnitude of the partial ring current and the size of the substorm disturbance. One method of measuring the size of the substorm disturbance is by the magnitude of the midlatitude positive bay. Figure 9 shows the results of plotting the magnitude of the field depression near dusk against the magnitude of the midlatitude positive bay for the 63 events selected for the investigation. Two linear least squares fits to the data were obtained by exchanging the dependent and independent variables. The correlation coefficient between the two variables is 0.3 which indicates little or no relationship.
Another method of estimating the size of the substorm disturbance is by computing a time integral of the $A L$ index. The limits on the integral are an important consideration since we wish to compare measures of substorm activity and measures of the interplanetary plasma conditions to measures of partial ring current development. It is well established that substorm activity follows variations of the IMF $B_{z}$ component with a time delay typically ranging from about $15 \mathrm{~min}$ to $80 \mathrm{~min}$ [Arnoldy, 1971; Foster et al., 1971; Kokubun, 1972; Rostoker et al., 1972; Tsurutani and Meng, 1972; Meng et al., 1973]. Thus, it is necessary for the integral to be started before the substorm onset. Since we have required each event to be isolated, we have eliminated the problem of overlapping integrations. The integration limits chosen in this investigation are based on the onset of the midlatitude positive bay and are taken from 2 


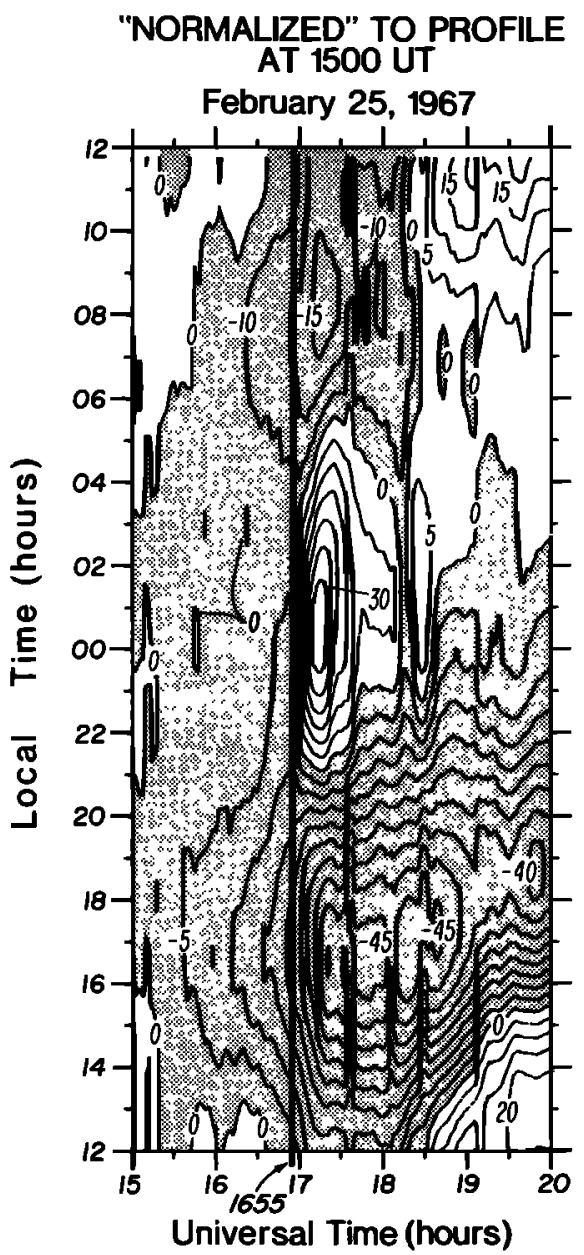

Fig. 7. UT-LT map of the midlatitude magnetic disturbance 'normalized' to 1500 UT. The local time profile at 1500 UT has been subtracted from all subsequent profiles. The map thus displays the magnetic perturbations caused by currents which develop in the time interval 1500-2000 UT. The vertical line at 1655 UT marks the substorm expansion onset.

hours before the midlatitude onset to the end of the midlatitude recovery.

Figure 10 shows the results of plotting the magnitude of the partial ring current against the time integral of the $A L$ index. The format is the same as Figure 9. The correlation coefficient is 0.29 which indicates little or no correlation between the size

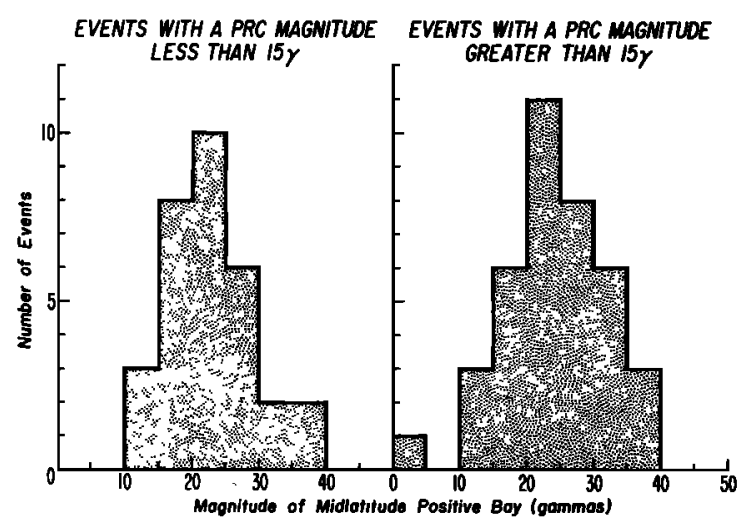

Fig. 8. The distributions of substorm associated midlatitude positive bay magnitudes for two classes of events defined by the magnitude of the partial ring current disturbance.

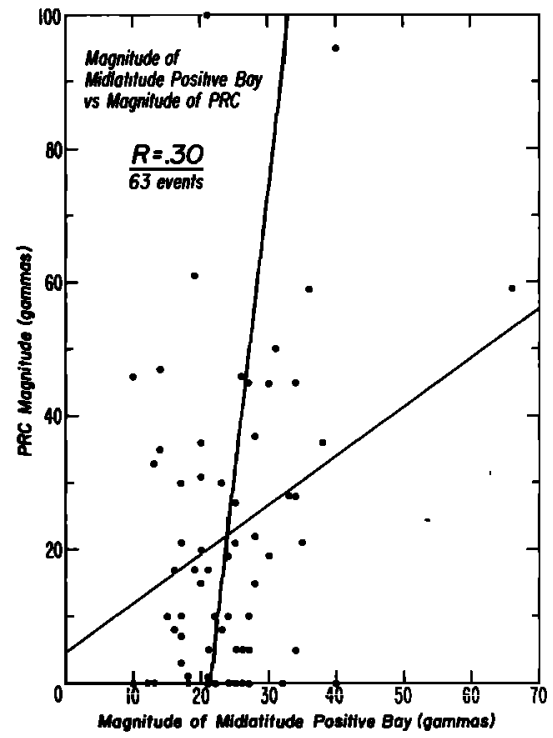

Fig. 9. Scatter plot of the magnitude of the midlatitude positive bay versus the magnitude of the associated partial ring current field depression.

of the substorm activity and the magnitude of the associated partial ring current.

Using the same integral limits, the time integral of the dawn to dusk component of the IEF is related to the magnitude of the partial ring current in Figure 11. Only periods of southward $B_{z}$ were included in the integral. A much higher correlation coefficient $(0.70)$ is obtained. This indicates that the strength of the partial ring current is more directly related to the strength and duration of the duskward IEF than to the size of the associated substorm activity.

The results obtained by examining temporal relationships will be discussed next. In this investigation we used only those events which had moderate to large partial ring currents. This restriction is necessary because of the difficulty in choosing the onset time for the partial ring current. Larger events tend to have a more well defined onset.

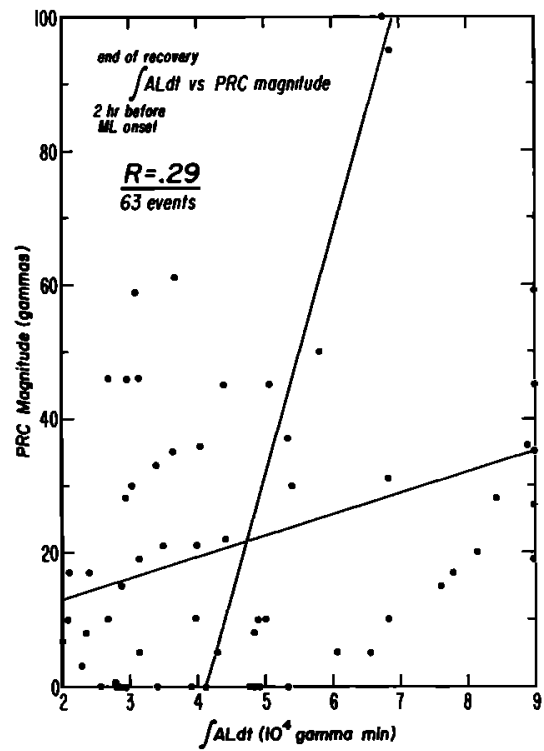

Fig. 10. Scatter plot of the time integral of $A L$ versus the magnitude of the associated partial ring current field depression at midlatitudes. The limits on the integral are 2 hours before the onset of the midlatitude positive bay to the end of the substorm recovery. 


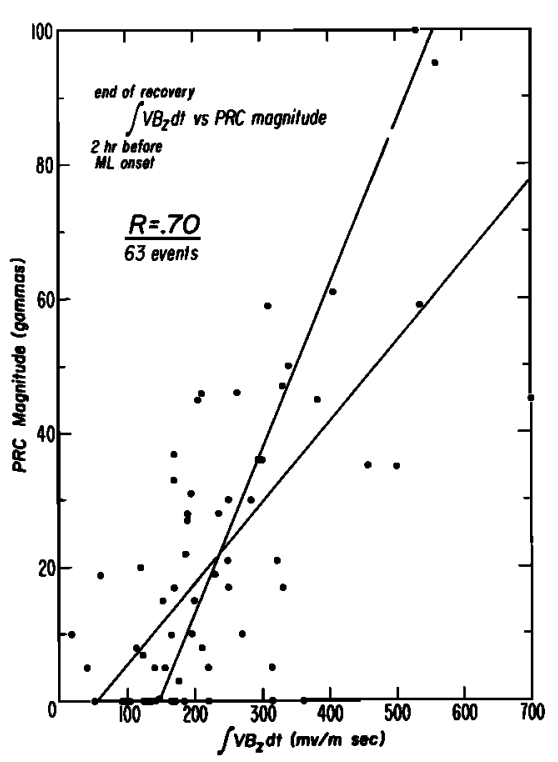

Fig. 11. Scatter plot of the time integral of the duskward interplanetary electric field $V B s$ versus the associated partial ring current field depression at midlatitudes. Only periods of southward $B_{z}$ are included in the integral. The limits on the integral are the same used in Figure 10.

In Figure 12 we show a histogram of the delay times between the onset of the midlatitude positive bay associated with the substorm expansion and the onset of the field depression near dusk for the events having a moderate to large partial ring current. Negative values of $\Delta t$ indicate that the magnetic field depression near dusk began prior to the positive bay onset. The histogram is made using $15 \mathrm{~min}$ bins. As discussed earlier, one can generally determine the onset within $\pm 15 \mathrm{~min}$. Note that although the peak at $\Delta t=0$ is large, about half of the events fall on the negative $\Delta t$ portion of the axis. Thus the development of the partial ring current begins prior to the onset of the midlatitude positive bay in many cases.

In Figure 13 we have further restricted our investigation to

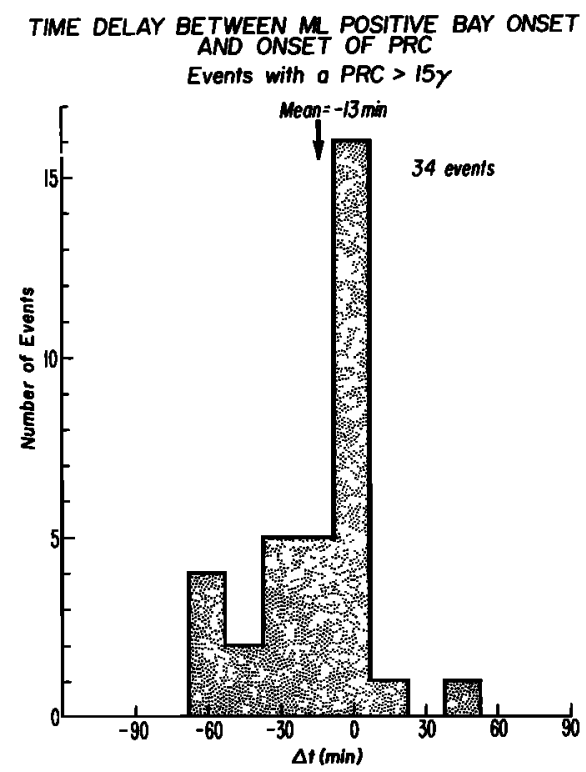

Fig. 12. The distribution of the time delay between the onset of the midlatitude positive bay and the onset of the midlatitude partial

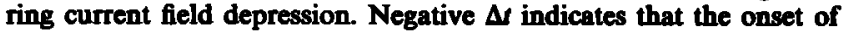
the partial ring current depression occurs before the onset of the midlatitude positive bay.

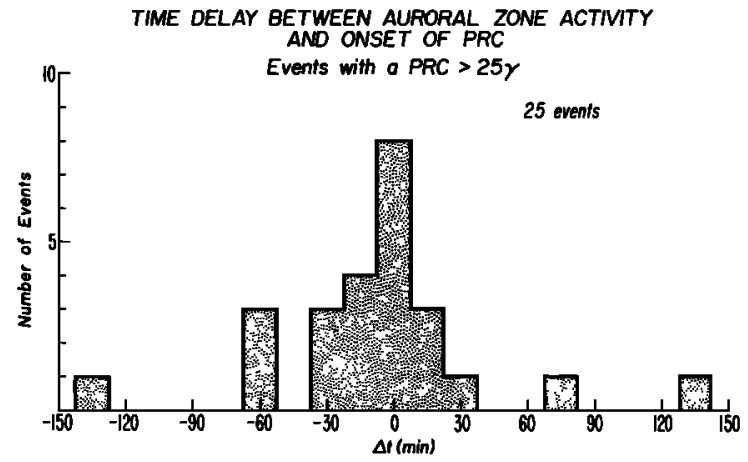

Fig. 13. The distribution of the time delay between the onset of auroral zone activity and the onset of the midlatitude partial ring current field depression. Negative $\Delta t$ indicates that the onset of the partial ring current depression occurs before the onset of the auroral zone activity. Only events for which the PRC magnitude developed to be greater than $25 \gamma$ were used.

events with large (PRC $>25 \gamma$ ) partial ring current disturbances in order to reduce the ambiguity in determining the onset time of the disturbance. Figure 13 shows the histogram obtained by plotting the delay time between the auroral zone negative bay and the onset of the midlatitude field depression near dusk. Again the histogram is created using $15 \mathrm{~min}$ bins. In this case also, the results indicate that the onset of the partial ring current is as likely to occur prior to the onset of the auroral zone negative bay as it is to occur after.

Figure 14 shows the results when we examine the time delay between the closest associated southward turning of the IMF and the onset of the partial ring current for the same events examined in Figure 13. This demonstrates that the onset of large partial ring currents are consistently preceded by a southward turning of the IMF. The peak of the distribution is located at about $\Delta t=30 \mathrm{~min}$ and the mean $\Delta t$ is $49 \mathrm{~min}$.

\section{Discussion AND CONClusions}

In the preceding section we investigated the development of the partial ring current and its relation to individual substorm expansions and to interplanetary plasma conditions. The results indicate that the partial ring current is likely to begin growth before a substorm onset and that the magnitude of the partial ring current does not correlate well with the size of the associated substorm activity. A good correlation, however, exists between the time integral of the dawn to dusk directed IEF and the magnitude of the partial ring current. In addition, all of the large magnetic field depressions near dusk (PRC $>25 \gamma$ ) were preceded by enhancements of the dawn to dusk IEF.

These results do not suggest that substorms do not affect the partial ring current. In fact, the rate of magnetic field decrease at dusk frequently increases at the onset of a substorm expansion. The results of this study, however, do suggest that an enhancement of the electrostatic field within the magnetosphere plays a direct role in the formation of the partial ring current. A similar conclusion has been reported by Blanc [1978]. Enhancements of the northward ionospheric electric field measured by the Saint Santin incoherent scatter radar $(L \simeq 1.8)$ at dusk were shown to be associated with a large southward turning of the IMF and decreasing Dst. The observations were interpreted to indicate that a suddenly enhanced electrostatic field in the magnetosphere penetrates to very low $L$ values and is closely associated with ring current enhancement. Enhancements of the ionospheric electric field and Dst decreases 
did not relate systematically to individual polar substorms. The results obtained by Blanc were based on $2.5 \mathrm{~min}$ resolution $A E$ and on hourly average values of the IMF and $D s t$. The results presented in this report are consistent with Blanc's conclusions and are based on higher time resolution data using parameters sensitive to the partial ring current.

Kamide [1974] showed that growth of the DR field on the earth's surface is more closely correlated with time variations of the IMF north south component than with the $A L$ index. He notes that while it has been generally accepted that low latitude negative bays are closely associated with the growth of the polar electrojet, the correlation is not always high, especially during periods of $B_{z}$ north.' Kamide offered two possible reasons for this result: (1) the DR field is a better measure of the energy involved in substorms than the DP field and (2) the present network of high latitude observatories is not always sufficient for monitoring the growth of the auroral electrojet. In this report we have offered a third explanation consistent with the observations: that an enhancement of the solar wind emf applied across the magnetosphere plays a direct causative role in partial ring current growth.

A paradox arises, however, since a strong correlation has been demonstrated to exist between southward IMF and auroral zone activity measured by $A L$ or $A E$. Why then do two quantities which are well correlated correlate so differently to a third quantity (PRC magnitude)?

The resolution of the paradox lies, we feel, in the different methodologies employed by the different analyses. For example, Holzer and Slavin [1979] have demonstrated that a very high correlation $(0.94)$ between $\int A l d t$ and $\int V B s d t$ can be obtained if one is careful about the limits used on the integrals. The high correlation was obtained by integrating from a very quiet period to a very quiet period or from magnetospheric 'ground state' to 'ground state.' The length of the integrations ranged from 4 hours to 126 hours. The high correlation is largely the result of including active period of very long duration.

The relationship between $\int A l d t$ and $\int V B s d t$ is poor when one considers individual isolated substorms. Figure 15 shows this relationship for the events used in this study and the same limits on the time integrals used to obtain Figures 10 and 11. The correlation coefficient is 0.46 which indicates a very weak relationship. A physical interpretation of this result is that,

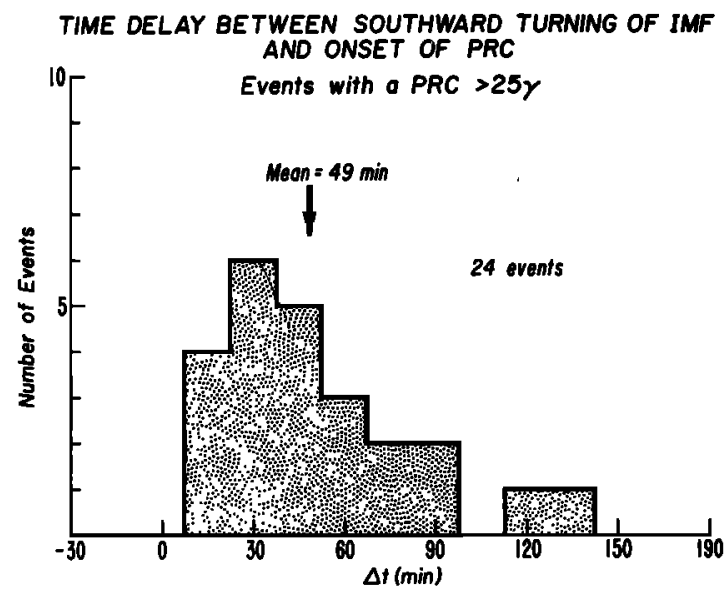

Fig. 14. The time delay between a southward turning of the IMF and the onset of the midlatitude partial ring current field depression. Positive $\Delta t$ indicates that the onset of the partial ring current depression follows the southward turning of the MMF. This distribution was computed using the same events used for Figure 13.

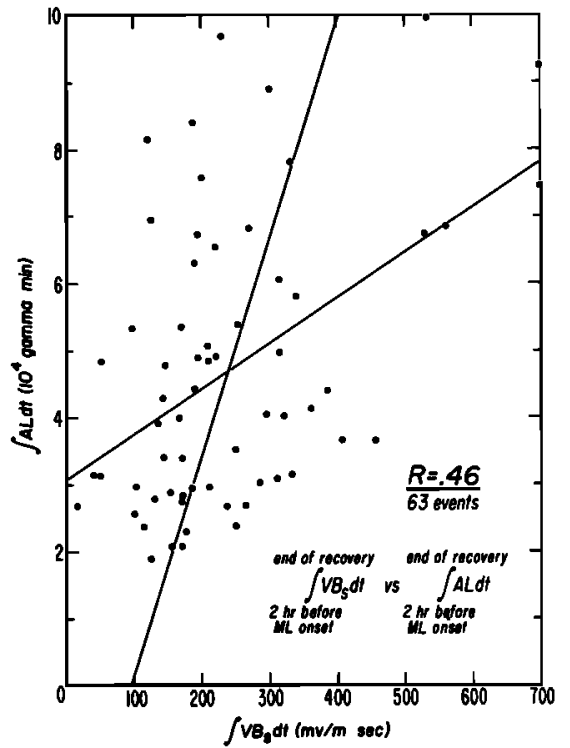

Fig. 15. Scatter plot of the time integral of the duskward interplanetary electric field $V B s$ versus the time integral of the $A L$ index for the same data displayed in Figures 9 and 10.

while substorms over the long term dissipate as much energy as was extracted from the solar wind, any individual substorm may release only a portion of the available energy.

Other investigators have reported correlations between southward IMF and $A E$ using different techniques [Wilcox et al., 1967; Arnoldy, 1971; Foster et al., 1971; Kokubun, 1971, 1972; Meng et al., 1973; Murayame and Hakamada, 1975]. An important difference is the selection of individual isolated substorms with well defined midlatitude signatures used in this investigation. The difference in the results, we feel, lies in the different methodologies employed in the investigations. We suggest that this poses an interesting question, and that additional study to understand the physical cause of these results is desirable.

To summarize, we have presented the results of an investigation of the relationship of the partial ring current to substorm activity and to interplanetary electric field. Individual isolated substorms which had clearly defined midlatitude signatures were selected for the analysis. Parameters of the partial ring current and substorm activity were created using $\mathbf{2 . 5}$ min resolution data. The results indicate that:

1. The magnitude of the partial ring current disturbance does not correlate well with the magnitude of the substorm disturbance.

2. The magnitude of the partial ring current correlates well with the time integral of the dawn to dusk IEF.

3. The partial ring current frequently begins to develop prior to a substorm onset.

4. The onset of large partial ring current disturbances are consistently preceded by an enhancement of the dawn to dusk IEF with a mean time delay of $48 \mathrm{~min}$.

We suggest that these results indicate an enhancement of the solar wind emf applied to the magnetosphere plays a direct causative role in partial ring current development.

\section{Note Added in Support}

We would like to note the recent work presented by Harel et al. [1979], Spiro et al. [1979], and Chen et al. [1979] at the spring meeting of the American Geophysical Union and the recent report of Harel et al. [1980]. This work is particularly 
interesting and important because it demonstrates using simulation techniques that enhancement of the partial ring current results from an enhancement of externally (solar wind) driven convection rather than substorm processes. In fact, the substorm simulated in their work has virtually no influence on the development of the partial ring current.

Acknowledgments. The major portion of this investigation was supported by the Office of Naval Research under grant ONR NOOO1475-C-0396. Partial assistance was provided by NASA grant NGL 05007-004 and NSF grant ATM 76-17035. We gratefully acknowledge the Regents of the University of California for providing partial support of the computing. Digitized ground magnetic date were provided by the World Data Center A for Geomagnetism. We thank J. Binsack for the Explorer 33 and'35 plasma data and C. P. Sonett and D. S. Colburn for the Explorer 33, 35 magnetic field data. We also gratefully acknowledge many helpful discussions regarding this investigation with M. G. Kivelson, R. J. Walker, and C. T. Russell.

\section{REFERENCES}

Akasofu, S.-I., and S. Chapman, On the ayymmetric development of magnetic storm fields in low and middle latitudes, Planet. Space Sci, 12, 607, 1964.

Akasofu, S.-I., and C.-I. Meng, Low latitude negative bays, J. Atmos Terr. Phys., 30, 227, 1968.

Arnoldy, R. L., Signature in the interplanetary medium for substorms, J. Geophys. Res., 76, 5189, 1971.

Blanc, M., Mid-latitude convection electric fields and their relation to ring current development, Geophys. Res. Lett., 5, 203, 1978.

Bogoth, F. H., and F. S. Mozer, ATS 5 observations of energetic proton injection, J. Geophys. Res., 78, 8113, 1973.

Burton, R. K., R. L. McPherron, and C. T. Russell, An empirical relationship between interplanetary conditions and $D$ st, J. Geophys. Res., 80, 4204, 1975.

Cahill, L. J., Jr., Inflation of the inner magnetosphere during a magnetic storm, J. Geophys. Res., 71, 4505, 1966.

Cahill, L. J., Jr., Magnetosphere inflation during four magnetic storms in 1965, J. Geophys. Res., 75, 3778, 1970.

Cahill, L. J., Jr., Magnetic storm inflation in the evening sector, $J$. Geophys. Res., 78, 4724, 1973.

Chen, A. J., Penetration of low-energy protons deep into the magnetosphere, J. Geophys. Res., 75, 2458, 1970.

Chen, A. J., Correction, J. Geophys. Res., 79, 5314, 1974.

Chen, C. K., M. Harel, R. A. Wolf, and A. C. Calder, Substorm simulation results, III, Calculation of ground magnetic disturbance (abstract), Eos Trans. AGU, 60, 327, 1979.

Clauer, C. R., and R. L. McPherron, Mapping the local time universal time development of magnetospheric substorms using mid-latitude magnetic observations, J. Geophys. Res., 79, $2811,1974$.

Clauer, C. R., and R. L. McPherron, On the relationship of the partial ring current to substorms and the IMF, J. Geomagn. Geoelec., 30, $195,1978$.

Clauer, C. R., M. N. Casn, and R. L. McPherron, Non-uniformity in the substorm response of mid-latitude magnetic observatories: Physical causes and compensatory scaling factors (abstract), Eos Trans. AGU, 54, 415, 1973.

Clauer, C. R., R. L. McPherron, and M. G. Kivelson, Uncertainty in ring current parameters due to the quiet magnetic field variability at mid-latitudes, J. Geophys. Res., 85, 633, 1980.

Coleman, P. J., Jr., and W. D. Cummings, Simultaneous magnetic field variations at the earth's surface and at synchronous, equatorial distance, 2, Magnetic storms, Radio Sci., 3, 762, 1968.

Cowley, S. W. H., and M. Ashour-Abdalla, Adiabatic plasma convection in a dipole field: Electron forbidden-zone effects for a simple electric field model, Planet. Space Sci, 24, 805, 1976a.

Cowley, S. W. H., and M. Ashour-Abdalla, Adiabatic plasma convection in a dipole field: Proton forbidden-zone efiects for a simple electric field model, Planet. Space Sci., 24, 821, 1976 b.

Cummings, W. D., Asymmetric ring current and the low latitude disturbance daily variation, J. Geophys. Res., 71, 4495, 1966.

Cummings, W. D., J. N. Barfield, and P. J. Coleman, Magnetospheric substorms observed at the synchronous orbit, J. Geophys. Res., 73, 6687, 1968.

Davis, T. N., and R. Parthasarathy, The relationship between polar magnetic activity DP and growth of the geomagnetic ring current, J. Geophys. Res., 72, 5825, 1967.

DeForest, S. E., and C. E. Mcllwain, Plasma clouds in the magnetosphere, J. Geophys. Res., 76, 3587, 1971.

Ejiri, M., Trajectory traces of charged particles in the magnetosphere, J. Geophys. Res., 83, 4798, 1978.

Ejiri, M., R. A. Hoffiman, and P. H. Smith, The convection electric field model for the magnetosphere based on Explorer 45 observations, J. Geophys. Res., 83, 4811, 1978.

Foster, J. C., D. H. Fairfield, K. W. Ogilvie, and T. J. Rosenberg, Relationship of interplanetary parameters and occurrence of magnetospheric substorms, J. Geophys. Res., 76, 6971, 1971.

Frank, L. A., On the extraterrestrial ring current during geomagnetic storms, J. Geophys. Res., 72, 3753, 1967.

Frank, L. A., Direct detection of asymmetric increases of extraterrestrial 'ring current' proton intensities in the outer radiation zone, J. Geophys. Res., 75, 1263, 1970.

Fukushima, N., Polar magnetic substorms, Planet. Space Sci., 20, $1443,1972$.

Fukushima, N., and Y. Kamide, Partial ring current models for worldwide geomagnetic disturbances, Rev. Geophys. Space Phys, Il, 795, 1973.

Harel, M., R. A. Wolf, P. H. Reiff, and R. W. Spiro, Substorm simulation results, I, General formulation and energy budget (abstract), Eos Trans. AGU, 60, 327, 1979.

Harel, M., R. A. Wolf, R. W. Spiro, P. H. Reiff, C.-K. Chen, W. J. Burke, F. J. Rich, and M. S. Smiddy, Quantitative simulation of a magnetospheric substorm, 2, Comparison with observations, Dep. of Space Phys. and Astron., Rice Univ., Houston, Tex., 1980.

Holzer, R. E., and J. A. Slavin, A correlative study of magnetic flux transfer in the magnetosphere, J. Geophys. Res., 84, 2573, 1979.

Huage, R., and F. Soraas, Precipitation of $>115 \mathrm{keV}$ protons in the evening and forenoon sectors in relation to the magnetic activity, Planet. Space Sci., 23, 1141, 1975.

Jaggi, R. K., and R. A. Wolf, Self-consistent calculations of the motion of a sheet of ions in the magnetosphere, J. Geophys. Res., 78, 2852, 1973.

Kamide, Y., Association of DP and DR fields with the interplanetary magnetic field variation, $J$. Geophys. Res., 79, 49, 1974.

Kamide, Y., and N. Fukushima, Positive geomagnetic bays in evening high latitudes and their possible connection with partial ring current, Rep. Ionos. Space Res. Jap., 26, 79, 1972.

Kawasaki, K., and S.-I. Akasofu, Low-latitude DS component of geomagnetic storm field, J. Geophys. Res., 76, 2396, 1971.

Kivelson, M. G., and D. J. Southwood, Local time variations of particle flux produced by an electrostatic field in the magnetosphere, $J$. Geophys. Res., 80, 2074, 1975a.

Kivelson, M. G., and D. J. Southwood, Approximations for the study of drift boundaries in the magnetosphere, $J$. Geophys. Res., 80, 3528, $1975 b$.

Kokubun, S., Relationship of interplanetary magnetic field structure with development of substorm and storm main phase, Planet. Space Sci., 20, 1033, 1972.

Langel, R. A., and J. C. Cain, Ogo-2 magnetic field observations during the magnetic storm of March 13-15, 1966, Ann. Geophys., 24, 857, 1968.

Meng, C.-I., B. Tsurutani, K. Kawasaki, and S.-I. Akasofu, Cross-correlation analysis of the $A E$ index and the interplanetary magnetic field $B_{z}$ component, J. Geophys. Res., 78, 617, 1973.

Murayama, T., and K. Hakamada, Effects of solar wind parameters on the development of magnetospheric substorms, Planet. Space Sci, 23, 75, 1975.

Rostoker, G., Geomagnetic indices, Rev. Geophys. Space Phys., 10, 935, 1972.

Rostoker, G., H. L. Lam, and W. D. Hume, Response time of the magnetosphere to the interplanetary electric field, Can. J. Phys., 50, 544, 1972.

Smith, P. H., and R. A. Hoffman, Ring current particle distributions during the magnetic storms of December 16-18, 1971, J. Geophys. Res., 78, 4731, 1973.

Spiro, R. W., M. Harel, R. A. Wolf, P. H. Reiff, and F. J. Rich, Substorm simulation results, II, Subauroral electric fields and evolution of the plasmapause (abstract), Eos Trans. AGU, 60, 327, 1979.

Sugiura, M., and S. Chapman, The average morphology of geomagnetic storms with sudden commencements, $A b h$. Akad. Wiss. Goettingen Math. Phys. Kl., spec. issue 4, 53 pp., 1960. 
Troshichev, O. A., and Ya. I. Feldstein, The ring current in the magnetosphere and the polar magnetic substorms, J. Atmos. Terr. Phys., $34,845,1972$.

Tsurutani, B. T., and C.-I. Meng, Interplanetary magnetic field variations and substorm activity, J. Geophys. Res., 77, 2964, 1972.

Walker, R. J., and M. G. Kivelson, Energization of electrons at synchronous orbit by substorm-associated cross-magnetospheric electric fields, J. Geophys. Res., 80, 2074, 1975.

Wilcox, J. M., K. M. Schatlen, and N. F. Ness, Influence of inter- planetary magnetic field and plasma on geomagnetic activity dur=ing quiet sun conditions, J. Geophys. Res., 72, 19, 1967.

Wolf, R. A., Effects of ionospheric conductivity on convective flow of plasma in the magnetosphere, $J$. Geophys. Res., 75, 4677, 1970.

(Received December 18, 1979;

revised June 9, 1980;

accepted June 23, 1980.) 